\title{
SOBRE LA MILITANCIA REVOLUCIONARIA DE LOS INTELECTUALES ESCRITO DEL COMANDANTE RICARDO MORALES AVILÉS, MIEMBRO DE LA DIRECCIÓN NACIONAL DEL FSLN
}

Publicado originalmente en Taller, revista de los estudiantes de la UNAN, № 8, enero de 1972, pp. 49-58.

Se puede observar en la literatura actual de nuestro país, la irrupción vigorosa de temas sobre los problemas planteados por la realidad social y política. Los temas de honda preocupación humanista tienen la misma procedencia. Estamos ante la presencia de una literatura po-litizada (en el buen sentido del término. Y en el malo también). Sólo que no toda la literatura es consciente de esa "politización", ni toda tiene el mismo signo ni el mismo sentido.

¿A qué se debe que la temática humanista, social y política se halla a la vuelta del día? La razón general histórica, objetiva, es la transformación revolucionaria del mundo, los cambios revolucionarios que se operan, día a día, ante nuestros ojos. La razón particular, históricamente objetiva, ligada estructuralmente a esa transformación revolucionaria del mundo -pero específicamente nacional- es el cuestionamiento revolucionario ante el régimen político-social imperante en Nicaragua, detentado y mantenido por la burguesía oligárquica, a la cabeza la camarilla somocista, sostenida y sometida por el imperialismo; es la lucha popular por la destrucción de la dominación y la explotación capitalista para instaurar el poder del pueblo que asegurará a nuestros campesinos y obreros condiciones de vida y de desarrollo individual y colectivo no conocidos hasta ahora; es la aparición en estas condiciones de la fuerza organizada revolucionaria del pueblo y su enfrentamiento a las fuerzas reaccionarias capitalistas empeñadas, inútilmente, en salvar su dominación clasista. Estas transformaciones históricas condicionan y explican ciertas transformaciones mentales.

A nivel ideológico, la irrupción es la toma de posición y justificación frente a los cambios y la lucha. Se percibe fácilmente, incluso a nivel de conciencia periférica, que todo esto está mal. La historia lo está diciendo y la realidad cotidiana también. El hecho de estarlo viviendo y pensando indica que está mal. Los obreros y los campesinos en pie de lucha con voluntad autonómica y consciente. Esos valores largamente heredados, aceptados, asimilados, son ahora rechazados, impugnados, condenados a muerte inexorable. Inversión-ruptura desplazamiento. Nuevas perspectivas. Nuevas dimensiones y significaciones. Preparación del espíritu para la transformación del mundo. Vocación a partir de los supuestos ideológicos para una praxis cultural estética-política-social.

Esquemáticamente la operatividad política e ideológica puede tomar una de tres posiciones: a) O se defiende la explotación capitalista sin modificaciones ni mayores adecuaciones, y tenemos la burguesía reaccionaria: somocismo-agüerismo, negación total, abierta, del poder del pueblo; b) $O$ se defiende al capitalismo introduciéndole modificaciones, haciendo concesiones, reformándolo sin alterar la realidad y la sustancia de la explotación sutilmente enmascarada, y tenemos la burguesía reformista: social-cristianismo, nacional-popular conservadurismo, liberalismo democrático, apariencia de participación del pueblo en el poder; c) O Se lucha por la destrucción del capitalismo para establecer un sistema social superior y con ello tenemos las fuerzas revolucionarias del pueblo, obreros, campesinos, estudiantes e intelectuales revolucionarios: socialismo; Frente Sandinista, poder para el pueblo.

La posición-justificación- de los intelectuales, consciente-inconscientemente, se inscribe en estas tendencias de la operatividad político-ideológica nacional. Sólo que la realidad es más dialéctica que cualquier categorización, y más matizada; razones que hemos de tomar muy en cuenta a la hora de la crítica, de los enfrentamientos y de las relaciones. El intelectual quizás se preguntará y se identificará, o quizá ya lo hizo y se contestó y se identificó, o quizá se vaya preguntando y contestando e identificando. Lo que no puede es rehuir la toma de posición, no hay ninguna tierra de nadie.

Culturalmente hablando, los intelectuales o producen y renuevan la cultura para el gusto y la aceptación de la burguesía, y al servicio de su dominación; o instrumentalizan las formas y los medios culturales como arma revolucionaria al servicio del pueblo ¿Desempeñará el intelectual una función cultural dirigida al pueblo o será su posición una concesión a la burguesía y al imperialismo? 
Para el intelectual revolucionario la batalla cultural es la batalla por una nueva sociedad, por ello una nueva cultura desligada de la atracción de los comercialismos, modismos e intereses de la burguesía. La batalla por la cultura nacional, por nuevos personajes, por nuevo público, por nuevos actores, no puede desarrollarse por causas estrictamente culturales, por cuanto ese nuevo público, ese nuevo personaje -el pueblo- está estructural e instrumentalmente en conexión con la lucha revolucionaria.

El papel del intelectual en la lucha revolucionaria sobrepasa lo meramente cultural y estético, para incrustarse como cuestiones más profundas y de base como son las de la lucha por la existencia de una sociedad de hombres libres que trabajan por medios de producción comunes, y hagan uso de manera consciente de todas sus fuerzas individuales como una sola fuerza social, para garantizar la satisfacción social organizada de todos los individuos, y asegurar así, las condiciones materiales para una vida feliz.

Resulta irrisorio el punto de vista según el cual la cultura no tiene nada que ver con la lucha revolucionaria o está por encima de ella. Quienes así creen deberían pensar más y mejor en las razones anteriormente dichas, y en el hecho de que la lucha revolucionaria, conjunta la historia del pueblo, sus mejores jornadas, sus más nobles tradiciones, sus valores más altos e íntimamente caros, sus aspiraciones; y que la lucha revolucionaria, en todo su proceso, de la dialéctica de sus fuerzas y de sus triunfos, es la praxis generadora de las condiciones necesarias para una inagotable creatividad cultural y un inacabable desarrollo humano.

La lucha por la cultura no puede estar por encima de la lucha revolucionaria, ni siquiera es paralela, es parte integrante de ella, es uno de los frentes de lucha de la revolución. ¿Cómo hablar de cultura, de cultura nacional, de creatividad y desarrollo, de bienes y valores culturales humanos, de realizaciones personales al margen de la lucha concreta que diariamente se lleva a cabo en las calles, en el campo, en las fábricas, en las haciendas, en las universidades y colegios?

En la situación actual del pueblo, el hecho de que pueda existir una prodigiosa literatura, estéticamente hablando, no cambia en nada la realidad de la explotación, del hambre, del analfabetismo, de la miseria. Para poner un ejemplo: los brillantes éxitos pictóricos y de premios de Armando Morales no tienen ningún significado ni sentido para el pueblo, a no ser los de hacerle más evidente la cultura de la miseria y la miseria de la cultura.
El intelectual revolucionario participa, al igual que los demás, de la necesidad de expresar la inquietud de un país en trance de revolución. Una preocupación de expresar una convicción, la conciencia de la situación y de una nueva realidad de acción, pero se da cuenta que la nueva solución de los problemas y la liberación del pueblo no pueden venir principal y exclusivamente del ámbito de la cultura, sino a través de una acción revolucionaria, global y diferenciada; desplegada a partir de una prolongada lucha político-militar.

Ahora que el pueblo ha emprendido su lucha políticomilitar por su liberación, la cultura y la producción cultural cambian de sentido. "Hacer cultura es precisar las ideas que han de cristalizar la voluntad popular para el combate. Hacer trabajo intelectual, es unirse al pueblo en su lucha y a su movimiento. De aquí las responsabilidades del intelectual revolucionario y el desafío a que lo tiene sometido la realidad del país. De aquí también la tarea fundamental que ha de cumplir: "emigrar" hacia el pueblo".

La "migración" hacia el pueblo es el meollo del asunto. Ir al pueblo quiere decir, ir a los campesinos y a los obreros. Ir al proletariado. Para la literatura y el arte, para toda la actividad cultural, en la batalla por el personaje perdido. No nos explicaremos debidamente los más rudimentarios fenómenos de la vida nicaragüense, si no descendemos hasta los obreros y los campesinos.

Hay que ir a la historia del pueblo, la pasada y la presente. Redescubrirlo. No es que antes haya faltado el acercamiento, ni que estuviera ausente la denuncia de las condiciones económicas, sociales y políticas del pueblo, expresadas en la obra literaria, en el ensayo, la publicación científica o política. No es eso. Sólo que no se trata del sustentamiento cariñosamente amargo de Joaquín Pasos, ni tampoco en la evocación idílica del campesinado -invocación del reino devoradode Pablo Antonio Cuadra, ni mucho menos la falsa denuncia que de sí mismos hacen los funcionarios de la oligarquía agro-explotadora y que sólo se dirigen al pueblo para inventariar recursos y explotarlo más y mejor.

Ni liberalismo sentimental, ni feudalismo cristiano, ni hipocresía capitalista. Hay que cambiar de signo y sentido. Producir culturalmente en la óptica de la dimensión popular. Producir y actuar en la órbita y la dimensión de la lucha de liberación nacional. El intelectual revolucionario ha de servir de vehículo para una mayor y mejor inteligencia de la realidad del proceso histórico, de la lucha del pueblo y su organización revolucionaria. 
El caso de Manolo Cuadra es aleccionador. En su producción se reflejan los problemas de su tiempo, su sensibilidad social le permite percibir las manifestaciones sociales y extraer de este fondo social - nutricio, su inspiración. En contacto con la lucha popular antiimperialista de Sandino, su conciencia intelectual se politiza y entrevé desde entonces la posibilidad revolucionaria del pueblo nicaragüense. La honestidad de su ejercicio intelectual, la manifestación radical de su conciencia desembocaron en el camino de la acción política. No podía ser de otra manera.

En un período en el que ciertos grupos políticos e intelectuales buscaban una mayor libertad política y económica, en el marco de una distensión política internacional, -inquietud que no correspondía a la tradición política de dominación de la oligarquía terrateniente ni a los intereses del imperialismo yanqui en Nicaragua- Manolo entra en choque contra el déspota y la situación totalitaria que domina al país. Se radicaliza con sus contactos con los trabajadores, y las luchas sindicales: la explosión proletaria instituirá el poder al hombre, la rebelión del hombre contra su miseria, la explotación, las condiciones inhumanas.

Pero Manolo no logra precisar ni teórica ni políticamente el lugar del proletariado, el papel de los campesinos y obreros en la lucha política, ni el desarrollo de la lucha de clases, limitando su práctica política. En la debilidad de las fuerzas revolucionarias, apenas en nacimiento y la consiguiente inexistencia de su vanguardia política organizada, de un movimiento proletario consciente organizado, explica de manera histórica las limitaciones de Manolo. Pero abrió caminos en tiempos difíciles y hay que recordar sus ánimos a los intelectuales de hoy.

La producción intelectual será invitación y ayuda a la identificación, al reconocimiento de la realidad del pueblo, encuentro de su yo, conciencia de sí para sí. Esclarecimiento, definición, y profundización de los problemas de la situación nacional, cuyas soluciones las dará la lucha revolucionaria.

Todo un cambio en la personalidad del intelectual a través del trato con el pueblo, de las actitudes, de las críticas, de los diálogos con el pueblo, del estudio de la realidad, a través de lo que escribe, de lo que habla, de lo que actúa. Por medio del arte y la literatura, el intelectual revolucionario ofrece al pueblo, nuevas formas de percibir la realidad para lograr una reestructuración de su relación con el mundo, modificando sus relaciones con el mundo burgués. El intelectual es liberado de los mitos burgueses, por medio de su obra, le hace volar la mansedumbre de Sobre la militancia revolucionaria de los intelectuales Escrito del Comandante. la conciencia popular condicionándola para la lucha liberadora. Seguir, posibilitar, poner en movimiento, encaminar. Hacer al pueblo compañero de la creación intelectual, proporcionarle una realidad que ha de buscar y sugerir el camino para llegar a esa realidad.

Establecer un puente vivo entre el intelectual y el pueblo en mi país, con más de la mitad de su población analfabeta, en donde los campesinos y los obreros se hallan al margen de la cultura, es tarea que requiere poner en juego la imaginación creadora. Constituye un desafío estimulante a la actividad creadora del intelectual. El arte y la literatura han de inventar las posibilidades artísticas para dirigirse al pueblo.

Plantear la realidad artística o cultural en términos colectivos y no para la vocación de unos cuantos elegidos. Socializar, ensayar y desarrollar las formas artísticas por medio de una expresión colectiva. Poner en movimiento la cultura hacia donde se hallan reunidos los trabajadores.

Ir a las masas. Cambiar el escenario de acción de la literatura y el arte, de toda la cultura y ligarla al movimiento de las masas: a la calle, a la fábrica, a las haciendas, al campo, a los colegios, a los sindicatos. La experiencia de llevar la poesía a los estudiantes que se tomaron las iglesias es un punto de partida para ligar el arte a la lucha revolucionaria. Hay que pensar seriamente en las posibilidades de la poesía y narrativa oral para dirigirse a las masas.

Pensar la literatura y arte con criterio de élites y creer que las masas populares no son capaces de entender y apreciar el arte, es pensar con el criterio individualista de la propiedad privada capitalista (yo primero, sólo yo, yo contra todos); y desconocer, por un lado, la capacidad de invención y asimilación de los trabajadores, cuya práctica productiva los capacita y los sensibiliza para aprehender la realidad y comprender el desarrollo histórico y por otro, que la tibieza y el desinterés de las masas es consecuencia de la estructura de las relaciones sociales capitalistas y, por ello sólo un momento transitorio en su desarrollo. La realización del individuo tiene que ser la realización de todos. De todos y cada uno.

Para realizar la migración, el intelectual tiene que incendiar el lenguaje y acabar con los estereotipos conceptuales y decir un discurso diferente. No someterse al lenguaje aceptado y establecido. Cambio de conceptos y de lenguaje. "Escribir en contra del capitalismo con el bagaje mental y vocabulario que se derivan del capitalismo es perder el tiempo". Para liberar el lenguaje y los conceptos hay que asir la realidad de 
manera nueva, hay que adoptar el punto de vista del proletariado. Hay que romper el orden ideológico establecido, el conservadurismo mental impuesto por las oligarquías y el imperialismo, rompiendo las formas y las temáticas de la cultura, del arte y la literatura sacralizada por las clases dominantes.

El régimen social de nuestro país es sobreviviente de un mundo históricamente muerto. Hacienda raquítica, rodeada de la realidad de la explotación feudal y la dialéctica judeo-cristiana, la incipiente burguesía nicaragüense buscó su camino y su fortaleza entregándose al expansionismo de la burguesía imperialista.

Desde mediados del siglo XIX comienza a nutrirse del imperialismo en proporción excesiva a su asimilación, de manera que su dependencia respecto de éste se hizo total, y la penetración y la dominación abarcó la totalidad social: economía-política-ideología.

La burguesía comprendió desde entonces, que su existencia y su dominación de clase están en relación con la existencia y dominio del imperialismo (sólo que esto es un bumerang que recogido por los revolucionarios) y por ello, liberales o conservadores a su tiempo, han tenido como tarea vital facilitar y reforzar la penetración y la explotación adaptándolos a las circunstancias. La enajenación ideológica y cultural no se deja al azar. El maridaje oligárquico-imperialista se propone imponer-asentir-justificar-mantener su dominio y explotación sobre el pueblo.

Inculcar al pueblo patrones culturales y de conducta para que en su imaginación viva libre su condición real de explotado. Los intelectuales son atraídos a la órbita cultural imperialista.

Y la influencia de Coronel Urtecho en las inquietudes estéticas innovadoras de aquellos poetas ligados a la Vanguardia no es del todo inocente, histórica y políticamente hablando, como no lo son en absoluto las exposiciones y los premios de la Esso, como no podrían serlo las becas y los viajes que el imperialismo concede a los estudiantes, a los intelectuales y artistas.

El intelectual revolucionario tiene que vivir atento y militante frente a estas ayudas y promociones imperialistas, combatir la frustración y la distorsión de la cultura, de las tradiciones y la historia del pueblo. Poner al descubierto los modelos que de manera inconsciente obedecen los estudiantes e intelectuales y que están en relación con la tipología cultural que quiere imponer el imperialismo, evidenciar la distorsión de las necesidades de las masas trabajadoras, y los modelos de vida que se les pretenda hacer aceptar. El intelectual tiene que afinar el sentido crítico para distinguir en las manifestaciones ideológicas todo aquello que tienda a justificar y mantener la dominación burguesa. El reaccionarismo de Coronel Urtecho, el socialismo en libertad de Téfel, o el humanismo conciliar de Pablo Antonio Cuadra, tienen una misma identidad estructural e histórica, y una misma finalidad: justificar y fundamentar la dominación de la clase burguesa.

Se tratan de presentar los ideales de la burguesía como ideales de todo el pueblo, un dominio como gobierno del pueblo, las contradicciones de clase como oposición de ideas, ignorar la lucha de clases para hablar de los intereses y del ser humano, del hombre que no pertenece a ninguna clase y que no existe sino en la especulación. Pero no caigamos en el error de ignorar las diferencias que presentan entre ellas, reflejo de las contradicciones internas de la burguesía y de ésta con el imperialismo, agudizadas por la lucha popular.

En base a esto, agudizar nuevamente el juicio crítico y distinguir lo que de positivo puedan tener. De forma que, sin sentirnos tentados por sus temas y lenguaje, podamos enfrentamos a ellos, ya sea apoyándolos, transformándolos, combatiéndolos, según la situación concreta por la que atraviesa la lucha de clases y según se acerquen o se alejen de la lucha y de las posiciones revolucionarias.

De otra forma no podríamos entender de forma debida en relación a qué, la obra de Ernesto Cardenal es progresista y en relación a qué debe superarse. Nosotros valoramos mejor que nadie la crítica a que somete al capitalismo y al imperialismo, pero tenemos que decirle al padre Cardenal que la lucha antiimperialista conduce al socialismo científico y que las experiencias tipo Solentiname, a pesar de la sinceridad, la honestidad y los buenos propósitos de los hombres como él, son utilizadas por el imperialismo para la construcción de ilusiones y que por eso, para el pueblo, Solentiname no está a la orden del día, sino la lucha contra el imperialismo yanqui, la lucha contra la oligarquía burguesa, la lucha contra la camarilla somocista y sus seguidores. Hay que decirlo, tanto más que las posiciones cercanas a las revolucionarias son susceptibles de transformarse y desarrollarse.

Con lo positivo de las ideas hay posibilidades de entendernos, podemos discutir y esclarecer lo progresivo y lo incorporamos al patrimonio cultural del pueblo. 
La claridad teórica e ideológica nos permitirá entender y entendernos con la nueva producción literaria, criticar, esclarecer y desarrollar sus formas y sus contenidos y consecuencias ideológicas y derivaciones políticas. Pensándola en el contexto de nuestra situación histórica, podremos discutir la seudo enajenación de "Diario de un amigo" de Mario CajinaVega, el indiferentismo cínico de la "Paz con Vosotros" de Julio Cabrales, tan sólo para poner dos ejemplos.

Esto nos permitirá comprender y hacer comprender que la nueva problemática de la literatura es característica de las situaciones de ruptura revolucionaria en el seno de las relaciones de clase, que es una literatura de transición y que bajo la influencia intelectual revolucionaria, lo mejor de ella puede realizar el desplazamiento, la "migración" hacia el pueblo, y alejándose de la ideología burguesa, dar en la forma específica literaria, una obra de arte que revolucione lo artístico y se integre en la revolución social. Hay que valorar debidamente la honda apertura hacia la realidad de la nueva literatura: su voluntad de realismo.

Por último, pero no de último, el intelectual revolucionario tiene que organizarse e integrarse al movimiento revolucionario organizado. La organización revolucionaria en sus diferentes niveles y formas. De esta manera, la organización es la integradora del esfuerzo cultural en la voluntad liberadora del pueblo. De manera organizada las ideas adquieren una fuerza material incontenible. Lo que aporta el Frente Ventana a la historia de la lucha revolucionaria y a la historia del esfuerzo cultural, es fundamentalmente el resultado organizado de su praxis intelectual que busca elucidar los problemas de nuestra política social y fundamentar el movimiento popular revolucionario.

La obra personal de Fernando Gordillo hay que atenderla desde la actuación organizada en el frente de la cultura y las relaciones orgánicas con el movimiento revolucionario. Su obra literaria está comprometida con sus combates políticos y revolucionarios. Que la inmadurez de las fuerzas revolucionarias y sus relaciones con una distinta concepción política de la lucha revolucionaria no haya sabido estructurar la obra de Ventana en un proyecto global, que a un período de ajuste y de reorganización revolucionaria correspondiera un período de desorientación y atomización en el frente intelectual, que impidió la continuación de la obra de Ventana, además de la desaparición de Gordillo, no hacen sino evidenciar la necesidad de desarrollar la línea trazada por este intelectual y Ventana, y llevar la organización de los intelectuales en el movimiento revolucionario a nuevos niveles.

Esto que es una necesidad es también una posibilidad, ahora que el Frente Sandinista de Liberación Nacional se ha consolidado y su capacidad organizativa y su línea estratégica revolucionaria han sido establecidas a través de su rica experiencia científicamente esclarecida. Esta es la garantía para desarrollar a fondo la línea del Frente Ventana y oponerla a la línea seguida por la Generación Traicionada, que como actitud y pensamiento (ideología y política) sólo desaparecerá cuando desaparezca la burguesía y las relaciones sociales que le dan sustentamiento.

De manera organizada, el intelectual revolucionario, a través de una praxis científica-artística-literariapolítica, diferenciada y diferenciadora irá haciendo saltar la realidad ideológica de la burguesía. Hay que ir más lejos. En nuestro país la lucha armada está planteada como medio principal para alcanzar la liberación y tomar el poder, de manera que el intelectual no sólo ha de esgrimir el arma de la crítica, sino empuñar las armas. Para asumir plenamente su papel en la lucha revolucionaria, es el camino que han seguido los intelectuales como Leonel Rugama.

Sólo a través de la militancia revolucionaria organizada, podrán los intelectuales lograr una comprensión racional de la marcha y de los fines del movimiento revolucionario y participar de manera consciente en la transformación del mundo que se verifica ante nuestros ojos.

Cárcel de La Aviación, 1970. 